\title{
UJI DAYA HAMBAT ANTIFUNGI Candida Albicans TERHADAP UMBI BAWANG PUTIH (Allium sativum) DAN DAUN SAMBILOTO (Andrographis Paniculata Nees) MENGGUNAKAN METODE CAKRAM KERTAS
}

\author{
Yogie Irawan $^{1}$ Riky $^{2}$ \\ ${ }^{12}$ STIKes Borneo Cendekia Medika Pangkalan Bun \\ ${ }^{1}$ Email : masyuduk@gmail.com
}

\begin{abstract}
ABSTRAK
Telah dilakukan penelitian yang berjudul "Uji Daya Hambat Antifungi Candida albicans Terhadap Infusa Umbi Bawang Putih (Allium Sativum Linn) dan Infusa Daun Sambiloto (Andrographis P,Folium) Menggunakan Metode Cakram Kertas". Penelitian ini bertujuan untuk mengetahui apakah kombinasi umbi bawang putih dan daun sambiloto dapat berfungsi sebagai antifungi terhadap candida albican danuntuk mengetahui pada konsentrasi berapakah penggabungan umbi bawang putih dan daun sambiloto yang efektif sebagai antifungi Candida albicans. Uji daya hambat ini dilakukan dengan menggabungkan infusa umbi bawang putih dan daun sambiloto pada konsentrasi 50\%:50\%, 25\%:75\%, 75\%:25\%. Metode pengujian antifungi ini adalah metode difusi agar, dengan cakram kertas. Dari hasil penelitian uji daya hambat antifungi candida albicans terhadap infus umbi bawang putih (Allium Sativum Linn) dan infus daun sambiloto (Andrographis P,Folium) dapat disimpulkan bahwa infusa umbi bawang putih (Allium Sativum Linn) dan infus daun sambiloto (Andrographis P,Folium) mampu menghambat pertumbuhan jamur candida albicans, berdasarkan hasil penelitian yang telah dilakukan bahwa konsentrasi sampel yang digunakan yang dapat menghambat jamur candida albicans adalah konsentrasi $75 \%: 25 \%$.
\end{abstract}

Kata Kunci : bawang putih, daun sambiloto, candida albicans

\section{TEST OF ANTIBUNGI ANTIFUNGI Candida Albicans TOWARDS WHITE UMBI (Allium sativum) AND SAMBILOTO LEAVES (Andrographis Paniculata Nees) USING THE METHOD PAPER DISC}

\begin{abstract}
A study entitled "Candida albicans Antifungal Inhibition Test Against Garlic Bulbs (Allium Sativum Linn) Infusion and Sambiloto Leaf Infusion (Andrographis $P$, Folium) Using Paper Discs Method". This study aims to determine whether the combination of garlic bulbs and bitter leaves can function as an antifungal against Candida albican and to determine at what concentration of garlic and bitter leaf bitter leaves are effective as antifungal Candida albicans. This inhibition test was carried out by combining the tuber infusion of garlic and bitter leaf at a concentration of 50\%: 50\%, 25\%: 75\%, 75\%: 25\%. This antifungal testing method is the agar diffusion method, with paper discs. From the results of research on the inhibitory test of antifungal candida albicans against garlic tubers (Allium Sativum
\end{abstract}


Linn) infusion and bitter leaf infusion (Andrographis $P$, Folium), it can be concluded that garlic tuber infusion (Allium Sativum Linn) and infusion of sambiloto leaf (Andrographis P, Folium)) is able to inhibit the growth of the fungus Candida albicans, based on the results of research that has been done that the concentration of the sample used that can inhibit the fungus Candida albicans is a concentration of $75 \%: 25 \%$.

Keywords: garlic, bitter leaf, candida albicans

\section{PENDAHULUAN}

Indonesia merupakan negara yang kaya akan tumbuhan berkhasiat obat, tetapi masyarakat hanya mengolahnya dengan cara yang sangat sederhana. Pada saat ini sudah banyak orang menggunakan tumbuhan yang berkhasiat obat, karena efek sampingnya yang tidak terlalu besar bahkan hampir tidak ada. Ada pula yang menggunakan tumbuhan obat untuk menjaga kebugaran tubuh.

Pengobatan tradisional merupakan salah satu warisan budaya bangsa Indonesia yang perlu digali serta dikembangkan. Berbagai macam penyakit dapat diobati dengan cara memanfaatkan obat tradisional dari tanaman-tanaman tertentu yang murah serta mudah didapat. Pengobatan dengan menggunakan tanaman obat tradisional tersebut memiliki kelebihan yaitu efek samping yang ditimbulkan relatif lebih kecil.

Bawang putih merupakan bumbu dasar utama masakan di Indonesia. Bawang putih setelah diteliti dapat menyembuhkan penyakit jamur pada kulit dan sebagai antibiotik alami dalam tubuh manusia. Bentuk pengobatannya bisa dengan ekstrak, minyak, serta berbentuk infus (Gunawan,2004).

Sambiloto merupakan tumbuhan semak yang mempunyai banyak cabang yang berdaun. Sambiloto yang pahit ini ternyata selain dapat menyembuhkan masuk angin atau influenza, menurunkan demam, serta sakit kuning juga setelah diteliti dapat mengobati penyakit jamur pada kulit (Triwahyadi, 2007).

Candida albicans merupakan jamur dimorfik karena kemampuannya untuk tumbuh dalam dua bentuk yang berbeda yaitu sebagai sel tunas yang akan berkembang menjadi blastospora dan akan membentuk hifa semu. Perbedaan bentuk ini tergantung pada faktor eksternal yang mempengaruhinya. C. albicans memperbanyak diri dengan membentuk tunas yang akan terus memanjang membentuk hifa semu. Hifa semu terbentuk dengan banyak kelompok blastospora berbentuk bulat atau lonjong di sekitar septum. Pada beberapa strain, blastospora berukuran besar, berbentuk bulat atau seperti botol, dalam jumlah sedikit (Hendrawati, 2012).

Penyakit jamur yang disebabkan oleh spesies Candida disebut kandidiasis, dapat bersifat akut atau sub akut dan dapat mengenai mulut, vagina, kulit, kuku, bronki atau paru-paru, kadang-kadang dapat menyebabkan septikemia, endokarditis, atau meningitis (Anaissie, 2007).

Secara tradisional, masyarakat menggunakan daun sambiloto dan umbi bawang putih untuk menyembuhkan penyakit yang disebabkan oleh jamur. Namun penggunaannya dengan satu macam tanaman masih kurang efektif dalam 
menghambat pertumbuhan jamur. Hal ini yang melatarbelakangi penggabungan daun sambiloto dan umbi bawang putih yang dapat meningkatkan efektivitas suatu tanaman dalam menghambat pertumbuhan jamur.

\section{METODA PENELITIAN}

\section{Alat Penelitian}

Alat-alat yang digunakan dalam penelitian ini adalah cawan petri steril, beaker glass, inkubator, oven, autoklaf, aluminium foil, panci infus, jarum ose, neraca analitik, jangka sorong,pinset

\section{Bahan Penelitian}

Bahan yang digunakan pada penelitian ini adalah umbi bawang putih (Allium sativum), air suling,daunsambiloto

(Andrographis Paniculata Nees), medium PDA, dan jamur candida albicans.

\section{Prosedur Kerja}

\section{a. Penyiapan Sampel}

Sampel daun sambiloto dan umbi bawang putih yang diambil sebanyak masingmasing 1 genggam, dibersihkan dari kotoran-kotoran yang menempel pada permukaan daun dengan cara dicuci menggunakan air mengalir dari kotoran yang menempel.

b. Pembuatan infusa pada sampel penelitian

Konsentrasi infusa pada tanaman sambiloto dan bawang putih 50\%:50\%, 25\%:75\%, 75\%:25\% dibuat dengan cara timbang secara seksama sampel atau bahan, panaskan air sampai suhu $90^{\circ} \mathrm{C}$, setelah air mencapai suhu $90^{\circ} \mathrm{C}$ masukkan sampel tersebut ke dalam air mendidih dan direbus selama 15 menit. Setelah 15 menit, saring sedian infusa tersebut yang telah direbus selama 15 menit dan selanjutnya siap untuk dilakukan pengujian.

\section{c. Penyiapan Larutan Sampel}

Larutan sampel dibuat dengan masing-masing konsentrasi $100 \%$ infusa umbi bawang putih, $100 \%$ infusa daun sambiloto, 50\%:50\% infusa umbi bawang putih dan daun sambiloto, 25\%:75\% infusa umbi bawang putih dan daun sambiloto dan 75\%:25\% infusa umbi bawang putih dan daun sambilo.

\section{d. Sterilisasi Alat}

Alat-alat gelas yang akan digunakan untuk uji mikrobiologis dicuci dengan deterjen selanjutnya dibungkus dengan kertas perkamen dan disterilkan dengan oven pada suhu $170-180^{\circ} \mathrm{C}$ selama 2 jam.

\section{e. Uji dengan cakram kertas}

1) Sterilisasi alat, air suling dan medium PDA dilakukan dalam autoklaf pada suhu $110-115^{\circ} \mathrm{C}$ selama 20 menit.

2) Fungi dipelihara dalam agar miring, untuk percobaan digunakan biakan berumur 2 hari untuk candida albicans.

3) Pembuatan inokulum fungi dilakukan sebagai berikut, fungi disuspensikan di dalam air steril menggunakan jarum ose sampai homogen

4) Pembuatan lempeng agar dilakukan sebagai berikut, $15 \mathrm{ml}$ agar cair dicampur dengan $0,05 \mathrm{ml}$ inokolum fungi, dituang kedalam 
cawan petri, dibiarkan sampai menjadi padat.

5) Cakram kertas dicelupkan kedalam larutan yang diuji (ekstrak tanaman tsb) lalu diletakkan didalam lempeng agar dengan menggunakan pinset

6) Cawan petri diinkubasi pada $24-25^{0} \mathrm{C}$ selama 2 hari

7) Diameter hambatan diamati. (Anonim, 1993).

\section{f. Pengamatan}

Penentuan daya hambat pertumbuhan jamur uji dilakukan dengan mengukur luas daerah bening sekitar kertas saring dengan menggunakan jangka sorong, pengamatan dilakukan setelah diinkubasikan selama 2 hari.

\section{HASIL DAN PEMBAHASAN}

Pengujian daya hambat terhadap jamur Candida albicans yang merupakan penyebab penyakit kulit dilakukan dengan kombinasi infusa umbi bawang putih (Allium sativum linn) dan daun sambiloto (Andrographis Paniculata folium). Adapun dalam pengujian daya hambat ini digunakan konsentrasi $100 \%$ infusa daun umbi bawang putih, $100 \%$ infusa daun sambiloto, 50\%:50\% kombinasi infusa umbi bawang putih dan daun sambiloto, 25\%:75\% kombinasi infusa umbi bawang putih dan daun sambiloto, dan 75\%:25\% kombinasi infusa umbi bawang putih dan daun sambiloto. Pengujian ini dilakukan berdasarkan data secara empiris bahwa penggunaan kombinasi umbi bawang putih dan daun sambiloto dapat digunakan sebagai salah satu pengobatan alternatif pada penyakit kulit.
Diameter daerah hambatan infusa umbi bawang putih (Allium sativum linn) dan daun sambiloto (Andrographis Paniculata folium) terhadap pertumbuhan jamur Candida albicansdapat dilihat pada tabel 1 :

Tabel 1 Hasil Uji Daya Hambat

\begin{tabular}{|c|c|c|c|c|c|}
\hline \multirow{2}{*}{ Perlakuan } & \multicolumn{5}{|c|}{ Diameter Daerah Hambat (cm) } \\
\cline { 2 - 6 } & 1 & 2 & 3 & Jumlah & $\begin{array}{c}\text { Rata- } \\
\text { rata }\end{array}$ \\
\hline I & - & - & - & - & - \\
\hline II & - & - & - & - & - \\
\hline III & - & - & - & - & - \\
\hline IV & - & - & - & - & - \\
\hline V & - & 4,84 & 1,35 & 6.19 & 3,09 \\
\hline
\end{tabular}

Ket: $\mathrm{I} \quad=100 \%$ infusa umbi bawang putih

$$
\text { II } \quad=100 \% \text { infusa }
$$

daun sambiloto

$$
\text { III }=50 \% \text { infusa }
$$

umbi bawang putih : $50 \%$ infusa daun sambiloto

$$
\text { IV }=25 \% \text { infusa }
$$

umbi bawang putih : $75 \%$ infusa daun sambiloto

$$
\mathrm{V}=75 \% \text { infusa }
$$

umbi bawang putih : $25 \%$ infusa daun sambiloto

Pengujian daya hambat infusa umbi bawang putih (Allium sativum linn) dan daun sambiloto (Andrographis Paniculata folium) terhadap pertumbuhan jamur candida albicans menghasilkan zona hambat bahwa infusa umbi bawang putih (Allium sativum linn) dan daun sambiloto (Andrographis Paniculata folium) efektif dalam membunuh atau menghambat pertumbuhan jamur candida albicans pada konsentrasi 75\%:25\%, adanya zona/daerah bening disekeliling kertas saring yang diletakkan diatas permukaan medium yang telah ditanam dijamur uji dan 
kemudian di inkubasi selama 2 hari pada suhu $27^{0} \mathrm{C}$ setelah itu diukur diameternya dengan jangka sorong.

Larutan sampel $\mathrm{V}$ dengan konsentrasi (75\%:25\%) memberikan diameter rata-rata hambatan yaitu 3,09 $\mathrm{cm}$, sedangkan pada larutan sampel I (100\% infusa umbi bawang putih), II (100\% infusa daun sambiloto), III (50\%:50\%) dan IV (25\%:75\%) tidak memberikan diameter rata-rata daerah hambatan.

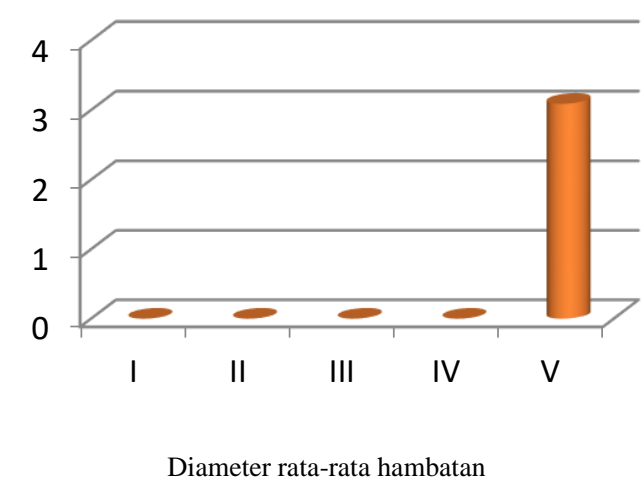

Gambar 2 Diagram Diameter RataRata Hambatan Infusa umbi bawang putih (Allium sativum linn) dan infusa daun sambiloto

(Andrographis Paniculata folium) Terhadap Pertumbuhan Jamur Candida Albicans

Daya hambat pertumbuhan jamur candida albicans tersebut kemungkinan disebabkan adanya kandungan senyawa antifungi dalam infusa umbi bawang putih dan infusa daun sambiloto. Hasil penelitian daya hambat pertumbuhan jamur candida albicans dengan menggunakan infusa umbi bawang putih dan infusa daun sambiloto yang memberikan daya hambat yaitu pada konsentrasi $75 \%: 25 \%$.
Uji fitokimia ekstrak bawang putih terbukti mengandung beberapa zat yaitu Triperpenoid dan saponin. Dimana triperpenoid merupakan komponen aktif dalam tumbuhan obat yang bekerja sebagai fungisida, insektisida, antibakteri. Sedangkan saponin memiliki daya racun terhadap jamur yang berhubungan dengan kemampuan senyawa ini untuk membentuk komplek dengan sterol membran dari sel jamur, dan menyebabkan pembentukan rongga yang $\quad=100 \%$ infusa umbi bawang an kerus putih ur (Mad II = 100\% infusa daun sambiloto bi bawa III $=50 \%$ at pertu] infusaumbibawangputih : Pada 50\% infusadaunsambiloto to

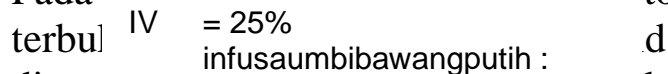
dima1 $75 \%$ infusadaunsambiloto b, $2005 \mathrm{~V}=75 \%$ as anti $\mathrm{k}$ infusaumbibawangputih : $\quad \mathrm{da}$ albice 25\% infusadaunsambiloto 3). Namı va fenol yang mudan rusak dan teroksidasi pada suhu tinggi (Markham, R.K. 1988), sehingga pengambilan ekstrak daun sambiloto dengan menggunakan pembuatan infusa tidak efektif dalam menghambat fungi Candida Albicans karena flavanoid dalam pemanasan telah rusak.

\section{Kesimpulan dan Saran}

\section{Kesimpulan}

Dari hasil penelitian uji daya hambat anti fungi candida albicans terhadap infusa umbi bawang putih (Allium sativum linn) dan infusa daun sambiloto (Andrographis Paniculata folium) dapat disimpulkan bahwa :

1. Infusa umbi bawang putih (Allium sativum linn) dan daun sambiloto (Andrographis Paniculata folium) mampu menghambat pertumbuhan 
pertumbuhan jamur candida albicans.

2. Berdasarkan hasil penelitian yang telah dilakukan bahwa konsentrasi sampel yang digunakan yang dapat menghambat jamur Candida albicans adalah konsentrasi $75 \%: 25 \%$.

3.

\section{Saran}

1. Sebaiknya dilakukan penelitian lebih lanjut untuk uji daya hambat anti fungi candida albicans terhadap infusa umbi bawang putih (Allium sativum linn) dan daun sambiloto

(Andrographis

Paniculata folium) sebagai pengobatan penyakit pada kulit dengan varian konsentrasi yang berbeda

2. Untuk melakukan uji toksisitas infusa daun sambiloto dan umbi bawang putih terhadap pertumbuhan jamur candida albicans.

\section{DAFTAR PUSTAKA}

Anaissie, E. J. The Changing Epidemiology of Candida Infection. Available from URL

Bonang, G., 1979, Mikrobiologi Kedokteran, 43, Gramedia Pustaka Utama, Jakarta Calderone, R.A., 2002, Candida and Candidiasis

Gunawan, D. dan S. Mulyani. 2004. Ilmu Obat Alam (Farmakognosi) Jilid 1.Penebar Swadaya.Jakarta.

Anonim, 2009, Anti Jamur Dengan Tumbuhan Obat, Klik Dokter mobile Version, diakses tanggal 13 Februari 2018
Cushnie T.P. And A..J. LAMB., 2005, Antimicrobial Activity of Flavonoid. J. Nat. Prod. 26(5): 343-356

David, R, 1991 , Bawang Putih Untuk Kesehatan, Jakarta : PT Bumi Aksara

Departemen Kesehatan RI, 1995, Farmakope Indonesia Edisi IV, Ditjen POM Depkes RI, Jakarta

I-Thomas A.N.S, 1989, Tanaman Obat Tradisional, Kanisius, Yogyakarta

Kusumaningtyas E., R.R.Widiati Dan D. Gholib, 2008, Uji Daya Hambat Ekstrak Dan Krim Ekstrak Daun Sirih (Piper Betle) Terhadap Candida Albicans Dan Trichophyton Mentagrophytes, Seminar Nasional Teknologi Peternakan dan Veteriner, Bogor

Lenita, M.,2009, Pengujian Daya Hambat Ekstrak Metanol Kulit Buah Manggis (Garcinia mangostana Linn) Terhadap Pertumbuhan JamurCandida Albicans, Karya Tulis Ilmiah, Akademi Farmasi Yarsi Pontianak, Pontianak (tidak dipublikasikan)

Made, S, 2009, Efektifitas Ekstrak Bawang Putih (Allium sativum) dalammenghambat pertumbuhan jamur Legenidium sp, penyebab penyakit pada albalon(Haliotis asinina), Bukit Jimbaran

Markham, R.K, 1988, Cara Mengidentifikasi Flavonoid, ITB, Bandung. 
Mccharty P.J., T.P. Pitts, Geewanda, M.K. Borges And S.A. Pomponi., 1992, Antifungal Activity Of Meridine, A Natural Product From The Marine Sponge Corticum Sp. J. Nat. Prod. 55(11): $1664-1668$

Rahayu, 2006 ,Uji Daya Inhibisi Ekstrak Kasar Flavonoid Sambiloto (Andrographis Paniculata Nees) dan Temu Putih (Curcuma Zedoaria Roscoe) Terhadap Aktivitas Tirosin Kinase Secara In Vitro, Bogor.

Rukmana, R, Ir., 1995, Budidaya

Bawang Putih, Kanisius, Yogyakarta

Setiawan, D, 1999, Atlas Tumbuhan Indonesia, Jilid 1, Trubus Agriwidya, Jakarta

Widyawati, T, 2007, Aspek Farmakologi Sambiloto, Fakultas Kedokteran, Sumatra Utara 